\title{
AVALIAÇÃO DE PERÍODOS DE COLETA TOTAL DE FEZES PARA DETERMINAR A DIGESTIBILIDADE APARENTE DOS NUTRIENTES EM EQÜINOS
}

\begin{abstract}
RESUMO - Foram conduzidos dois ensaios de digestão, objetivando comparar os valores de digestibilidade dos nutrientes da cana-de-açúcar e cana-de-açúcar mais milho, em diferentes dias de coleta de fezes. Foram utilizados cinco e quatro cavalos adultos sem raça definida no primeiro e segundo ensaios, respectivamente, com idade média de seis anos. Os animais foram distribuídos aleatoriamente em blocos casualizados, em que cada cavalo constituiu o bloco, e os dias de coleta de fezes, os tratamentos. No primeiro ensaio, foi avaliada a digestibilidade da cana-de-açúcar em seis dias de coleta de fezes (2, 3, 4, 5, 6 e 7 dias), e no segundo ensaio, estimou-se a digestibilidade da cana-de-açúcar e milho em
\end{abstract}

\author{
KLEBER VILLELA ARAÚJO ${ }^{1}$ \\ JOSÉ AUGUSTO DE FREITAS LIMA ${ }^{2}$ \\ ELIAS TADEU FIALHO
2
NDO LORIANO FRANCO \\ GUMERCINDO LORIANO FRANCO ${ }^{1}$
}

TERMOS PARA INDEXAÇÃO: Cana-de-açúcar, digestibilidade, eqüinos.

cinco dias de coletas de fezes (2, 3, 4, 5 e 6 dias). Não foram verificadas diferenças $(\mathrm{P}>0,05)$ entre os dias de coleta de fezes para estimar a digestibilidade dos nutrientes da cana-de-açúcar e cana-de-açúcar mais milho, porém, verificou-se aumento $(\mathrm{P}<0,05) \quad$ na digestibilidade da PB da cana-de-açúcar com milho, na coleta de dois dias. Os períodos de coleta total de fezes de dois a sete dias, para ensaios de digestão com equiinos alimentados apenas com volumosos, e de três a seis dias, para eqüinos submetidos a dietas mistas, mostraram-se bastante precisos. Dessa forma, sugere-se um período de cinco dias como forma de padronização de metodologia em ensaios de digestão com eqüinos.

\section{VALUATION OF FECAL TOTAL COLLECTION PERIOD TO DETERMINATE THE APPARENT DIGESTIBILITY OF NUTRIENTS IN EQUINE}

\begin{abstract}
Two digestion assays were carried out, with the objective to compare digestibility of sugar cane and sugar cane plus corn nutrients, in different fecal collection days. Five and four adult horses, without a defined breed and averaging 6 years of age, were utilized in assay 1 and 2, respectively. A randomized block design was used, with each horse considered as block and the days of fecal collection as treatments. In assay 1 , the digestibility of sugar cane in six days of the fecal collection (days 2, 3, 4, 5, 6 and 7) was evaluated; and in assay 2 , the digestibitlity of sugar cane plus corn
\end{abstract}

over five days of fecal collection ( days 2, 3, 4, 5 and 6) was estimated. There were no significance $(\mathrm{P}>0.05)$ between days of fecal collection to estimate digestibility of sugar cane and sugar cane plus corn nutrients. However, an increase $(\mathrm{P}<0.05)$ in the digestibility of the $\mathrm{CP}$ of the sugar cane plus corn, on the second day of collection was observed. The utilization of three to six and two to seven days of total fecal collection in digestion assays which equines, feed with a mixed diet or solely roughage, respectively, was very precise, and a standard five day, period is recomended.

INDEX TERMS: Sugar cane, digestibility, equine.

\footnotetext{
1. Pesquisadores Associados da FAV- UNB, Brasília., kvaraujo@unb.Br (Fiscal Federal Agropecuário - MAPA, Sede, Brasília).

2. Professor do Departamento de Zootecnia da UNIVERSIDADE FEDERAL DE LAVRAS/UFLA, Caixa Postal 37 37200-000 - Lavras, MG.
} 


\section{INTRODUÇÃO}

A análise bromatológica dos ingredientes é, sem dúvida, o primeiro passo para a avaliação das rações. Todavia, faz-se necessário o conhecimento da quantidade dos nutrientes presentes na ração que será aproveitada pelo animal, informação que é obtida medindo-se a digestibilidade dos nutrientes. A digestibilidade dos alimentos poderá ser mensurada por meio de vários métodos; no entanto, o método de coleta total de fezes, com uso de gaiolas metabólicas, é o mais utilizado em eqüinos. Uma das preocupações com esse método refere-se ao tempo de permanência dos animais nas gaiolas, podendo trazer desconforto para os mesmos e alterar os coeficientes de digestibilidade (Knapka et al., 1967).

De acordo com Olsson e Ruudvere (1955), uma série de fatores afeta a digestão nos eqüinos: individualidade do animal, composição química do alimento, capacidade de alimentação, tipo de trabalho, granulometria e conteúdo de água nos alimentos, velocidade de trânsito dos alimentos no trato digestivo e quantidade de fibra presente na ração. Alguns desses fatores têm sido intensamente estudados, mas no que se refere ao período necessário para a realização da coleta total de fezes num ensaio de digestão, ainda existem divergências. $\mathrm{Na}$ literatura, foram verificados relatos de período de coleta de fezes de três dias (Cymbaluk et al., 1989), cinco dias (Slade e Hintz, 1969), seis dias (Todd et al., 1995), sete dias (Manzano e Carvalho, 1978), oito dias (Veiga et al., 1974), dez dias (Knapka et al., 1967) e 12 dias (Lathrop e Bohstedt, citados por Vander Noot et al., 1967).

O período de coleta de fezes deverá ter uma duração suficiente para reduzir ao máximo os erros resultantes da excreção irregular de fezes e da variação diária no comportamento dos animais. Sendo assim, sabe-se que o fluxo da digesta no tubo digestivo dos animais é influenciado por vários fatores, como espécie, idade, estado fisiológico, exercícios, temperatura ambiente, ingredientes da dieta, tamanho da partícula, freqüência de alimentação e teor de fibra da ração (Warner, 1981). De acordo com Wolter (1975), a velocidade de trânsito do alimento no trato digestivo do cavalo está entre o que ocorre nos animais monogástricos não-herbívoros e nos ruminantes. Vander Noot et al. (1967) mediram o tempo de passagem do indicador óxido crômico pelo trato digestivo de cavalos adultos e obtiveram uma recuperação de $99,8 \%$ após as 96 horas do início da alimentação. Os autores concluíram que quatro dias de coletas são suficientes para experimentos de digestão; porém, sugeriram cinco dias para reduzir as diferenças individuais dos animais. Entretanto, Alexander, citado por Robinson e Slade (1974), usando partículas coloridas e Haenlein et al. (1966), usando óxido crômico, obtiveram $100 \%$ de recuperação nas 48 horas subseqüentes à alimentação. Hintz e Loy (1966) encontraram valores de tempo de passagem intermediários, e $99 \%$ das partículas de polietileno foram recuperadas 63 horas após a alimentação.

Objetivou-se nesta pesquisa comparar os valores de digestibilidade dos nutrientes de dieta exclusiva de volumoso e dieta mista, em diferentes dias de coleta de fezes, visando a padronizar o período de coleta de fezes em ensaio de digestão com eqüinos.

\section{MATERIAL E MÉTODOS}

Foram realizados dois ensaios de digestão com eqüinos utilizando gaiolas metabólicas desenvolvidas por Stillions e Nelson (1968) e ajustadas por Furtado e Tosi (1996). Utilizaram-se cavalos castrados sem raça definida, com idade média de 6 anos.

Em cada ensaio foi avaliado um alimento ou uma dieta, e os procedimentos experimentais foram os mesmos. No primeiro ensaio, foi avaliada a digestibilidade da cana-de-açúcar picada, utilizando cinco cavalos com peso médio de $308,3 \pm 9,8 \mathrm{~kg}$. No segundo ensaio, foi testada a combinação de $59 \%$ de cana-de-açúcar picada e $41 \%$ de milho grão inteiro com base na matéria seca, utilizando-se quatro cavalos com peso médio de $331,1 \pm$ $18,0 \mathrm{~kg}$.

Os tratamentos foram constituídos por dias de coleta de fezes; no primeiro ensaio, foram seis dias de coleta ( $2,3,4,5,6$ e 7 dias), e no segundo ensaio, foram cinco dias (2, 3, 4, 5 e 6 dias).

$\mathrm{O}$ período pré-experimental, com objetivo de adaptar os animais à gaiola metabólica e medir o consumo voluntário de alimento, para posterior ajuste, teve uma duração de 20 dias. Durante esse período, os cavalos eram soltos diariamente por duas horas em uma área sem cobertura vegetal para se exercitarem.

O período experimental teve uma duração de sete e seis dias para os ensaios um e dois, respectivamente. Os animais foram pesados ao entrar nas gaiolas, onde permaneceram durante todo o período experimental sem se exercitarem. $\mathrm{O}$ alimento foi fornecido a uma quantidade determinada no pré-experimento para que houvesse $10 \%$ de sobra, dividido duas vezes ao dia, às 8 e às 16 horas. A água foi fornecida à vontade para que houvesse sobra, permitindo, assim, medir a ingestão diária.

As coletas de fezes iniciaram-se 24 horas após o fornecimento do alimento ou da dieta testadas. As fezes foram coletadas duas vezes ao dia, às 7 e 15 ho- 
ras, retirando-se uma amostra de $10 \%$ por coleta, por cavalo, para formar uma amostra composta diariamente. A amostra de alimento, em cada arraçoamento, foi retirada diariamente para todos os animais. As sobras foram coletadas integralmente para cada animal e armazenadas separadamente para cada dia. Todo material coletado foi identificado e congelado a $10^{\circ} \mathrm{C}$, para posterior processamento e análise química. As amostras de alimento, fezes e sobras foram analisadas quanto aos teores de matéria seca (MS), proteína bruta (PB) e energia bruta (EB), de acordo com Silva (1998), e fibra em detergente neutro (FDN), segundo a metodologia descrita por Van Soest (1967) e Van Soest et al. (1991) (Tabela1).

Foi utilizado um delineamento em blocos casualizados, com seis tratamentos e cinco repetições (cavalo) no primeiro ensaio, segundo o modelo abaixo:

$y_{i j}=\mu+C_{i}+D_{j}+\varepsilon_{i j}, \quad$ sendo:

$\mathrm{y}_{\mathrm{ij}}$ - Valores de consumo e digestibilidade aparente dos nutrientes da cana-de-açúcar, referentes ao cavalo i e ao dia j;

$\mu$ - constante associada a todas as observações;

$\mathrm{C}_{\mathrm{i}}$ - efeito do cavalo $\mathrm{i}$, sendo $\mathrm{i}=1,2,3,4,5$;

$\mathrm{D}_{\mathrm{j}}$ - efeito do dia de coleta $\mathrm{j}$, sendo $\mathrm{j}=1,2,3,4,5,6$;

$\varepsilon_{\text {ij }}$ - erro aleatório associado a cada observação que, por hipótese, tem distribuição normal, média zero e variância $\sigma^{2}$.
No segundo ensaio, foi utilizado o mesmo modelo, porém com cinco tratamentos e quatro repetições. Os resultados foram analisados pelo programa computacional, SAEG - Sistema de Análises Estatísticas e Genética (Universidade Federal de Viçosa - UFV, 1997) e as médias, comparadas pelo teste Student Newman Keuls.

\section{RESULTADOS E DISCUSSÃO}

O consumo diário médio de matéria seca (MS), proteína bruta (PB), energia digestível (ED) e fibra em detergente neutro (FDN) da cana-de-açúcar exclusiva e cana-de-açúcar e milho encontram-se nas Tabelas 2 e 3 , respectivamente. Não foram verificadas diferenças ( $\mathrm{P}>0,05)$ para os consumos de MS e PB da cana-deaçúcar nos diferentes dias de coleta de fezes, ao passo que o consumo de ED foi maior $(\mathrm{P}<0,05)$ no período de coleta de seis e sete dias. O consumo de FDN da canade-açúcar com dois dias de coleta foi inferior $(\mathrm{P}<0,05)$ aos cinco, seis e sete dias. Pode-se notar que os maiores valores de ingestão de ED ocorreu nos períodos de coleta de seis a sete dias, sendo provavelmente relacionados a uma tentativa de atender à exigência de mantença dos animais, podendo esse fato ser verificado na tendência de aumento do consumo de MS nesses mesmos períodos.

TABELA 1 - Composição química média dos alimentos avaliados nos 2 ensaios (\% matéria seca).

\begin{tabular}{|c|c|c|c|c|}
\hline Ensaio \ alimento & $\mathbf{M S}^{1}(\%)$ & $\mathbf{P B}^{1}(\%)$ & $\mathrm{EB}^{1}(\mathrm{kcal} / \mathrm{kg})$ & $\operatorname{FDN}^{1}(\%)$ \\
\hline \multicolumn{5}{|l|}{ Ensaio 1} \\
\hline Cana-de-açúcar & 21,98 & 4,82 & 4244 & 61,67 \\
\hline \multicolumn{5}{|l|}{ Ensaio 2} \\
\hline Cana-de-açúcar & 24,11 & 4,24 & 4294 & 58,19 \\
\hline Milho & 89,66 & 9,03 & 4664 & 16,61 \\
\hline Milho+Cana & 50,98 & 6,20 & 4446 & 41,14 \\
\hline
\end{tabular}

${ }^{1}$ MS (matéria seca), PB (proteína bruta), EB (energia bruta) e FDN (fibra em detergente neutro). 
TABELA 2 - Consumo diário médio de matéria seca (MS), proteína bruta (PB), energia digestível (ED) e fibra em detergente neutro (FDN) da cana-de-açúcar com os respectivos erros-padrão, para os diferentes dias de coleta de fezes.

\begin{tabular}{ccccc}
\hline \multirow{2}{*}{ Dias de coleta } & \multicolumn{4}{c}{ Consumo diário médio } \\
\cline { 2 - 5 } & MS kg/dia & PB g/dia & ED $^{\mathbf{1}}$ Kcal/kg & FDN $^{\mathbf{1}} \mathbf{~ k g} / \mathbf{d i a}$ \\
\hline 2 & $2,53 \pm 0,41 \mathrm{a}$ & $129,20 \pm 17,97 \mathrm{a}$ & $5914 \pm 1087 \mathrm{~b}$ & $1,55 \pm 0,24 \mathrm{c}$ \\
3 & $2,56 \pm 0,43 \mathrm{a}$ & $134,90 \pm 20,14 \mathrm{a}$ & $5775 \pm 1109 \mathrm{~b}$ & $1,60 \pm 0,26 \mathrm{bc}$ \\
4 & $2,60 \pm 0,45 \mathrm{a}$ & $130,07 \pm 19,99 \mathrm{a}$ & $5861 \pm 1030 \mathrm{~b}$ & $1,63 \pm 0,27 \mathrm{abc}$ \\
5 & $2,64 \pm 0,47 \mathrm{a}$ & $131,62 \pm 21,23 \mathrm{a}$ & $5934 \pm 1122 \mathrm{~b}$ & $1,66 \pm 0,28 \mathrm{ab}$ \\
6 & $2,68 \pm 0,48 \mathrm{a}$ & $133,32 \pm 21,48 \mathrm{a}$ & $6256 \pm 1132 \mathrm{a}$ & $1,69 \pm 0,29 \mathrm{ab}$ \\
7 & $2,72 \pm 0,48 \mathrm{a}$ & $136,37 \pm 21,75 \mathrm{a}$ & $6362 \pm 1131 \mathrm{a}$ & $1,72 \pm 0,29 \mathrm{a}$ \\
\hline $\mathrm{CV}(\%)^{2}$ & 3,80 & 3,78 & 3,83 & 3,61 \\
\hline
\end{tabular}

${ }^{1}$ Médias seguidas de pelo menos uma mesma letra na mesma coluna não diferem entre si $(P>0,05)$ pelo teste de SNK

${ }^{2}$ Coeficiente de variação

TABELA 3 - Consumo diário médio de matéria seca (MS), proteína bruta (PB), energia digestível (ED) e fibra em detergente neutro (FDN) da cana-de-açúcar e milho grão, com os respectivos erros-padrão, para os diferentes dias de coleta de fezes.

\begin{tabular}{ccccc}
\hline \multirow{2}{*}{ Dias de coleta } & \multicolumn{4}{c}{ Consumo diário médio } \\
\cline { 2 - 5 } & MS kg/dia & PB g/dia & ED $^{\mathbf{1}}$ Kcal/kg & FDN $^{\mathbf{1}} \mathbf{~ k g / d i a}$ \\
\hline 2 & $4,01 \pm 0,16 \mathrm{a}$ & $261,72 \pm 7,94 \mathrm{a}$ & $13696 \pm 320 \mathrm{a}$ & $1,42 \pm 0,04 \mathrm{a}$ \\
3 & $3,66 \pm 0,15 \mathrm{~b}$ & $241,45 \pm 7,70 \mathrm{~b}$ & $12299 \pm 379 \mathrm{~b}$ & $1,34 \pm 0,04 \mathrm{~b}$ \\
4 & $3,66 \pm 0,15 \mathrm{~b}$ & $239,18 \pm 7,98 \mathrm{~b}$ & $12459 \pm 393 \mathrm{~b}$ & $1,36 \pm 0,05 \mathrm{ab}$ \\
5 & $3,67 \pm 0,17 \mathrm{~b}$ & $235,08 \pm 8,52 \mathrm{~b}$ & $12546 \pm 436 \mathrm{~b}$ & $1,39 \pm 0,05 \mathrm{ab}$ \\
6 & $3,67 \pm 0,17 \mathrm{~b}$ & $235,02 \pm 9,06 \mathrm{~b}$ & $12545 \pm 442 \mathrm{~b}$ & $1,42 \pm 0,06 \mathrm{a}$ \\
\hline $\mathrm{CV}(\%)^{2}$ & 1,68 & 1,49 & 1,70 & 2,69 \\
\hline
\end{tabular}

\footnotetext{
${ }^{1}$ Médias seguidas de pelo menos uma mesma letra na mesma coluna não diferem entre si $(P>0,05)$ pelo teste de SNK

${ }^{2}$ Coeficiente de variação
}

Na dieta composta de cana-de-açúcar e milho, verificou-se uma redução $(\mathrm{P}<0,05)$ no consumo de MS, PB e ED de dois para três dias de coleta, que se manteve inalterada até o sexto dia de coleta, contrari- ando, assim, os resultados obtidos no primeiro ensaio. Esse fato provavelmente é devido à combinação de cana-de-açúcar e milho, propiciando um maior aporte de energia e inibindo o consumo nos períodos finais 
de coleta de fezes. Possivelmente, o baixo consumo de cana-de-açúcar verificado no primeiro ensaio esteja relacionado com a concentração de produtos da digestão no intestino delgado, como a glicose celular, e a produção de ácidos graxos voláteis no ceco (Frape, 1992).

A ingestão de água em razão do consumo de matéria seca dos alimentos foi de 1,7 e 1,71 de água/kg de MS consumida, para os ensaios 1 e 2, respectivamente. Esses resultados estão dentro dos limites preconizados pela literatura, por meio da qual sugere-se um consumo de 2 litros de água por kg de MS consumida para cavalos adultos num ambiente uniforme (Frape, 1992).

Os resultados dos coeficientes de digestibilidade aparente da MS, PB, EB e FDN da cana-deaçúcar e cana-de-açúcar e milho encontram-se nas Tabelas 3 e 4, respectivamente. Não foram verificadas diferenças $(\mathrm{P}>0,05)$ entre os dias de coleta de fezes para estimar a digestibilidade dos nutrientes da canade-açúcar. Pode-se constatar que a partir de cinco dias de coleta, houve redução nos erros-padrão das médias dos coeficientes de digestibilidade dos nutrientes, demonstrando, assim, uma maior precisão na estimativa dessas médias. Dessa forma, apesar de não ter havido diferenças entre os dias de coleta de fezes (2, 3, 4, 5, 6 e 7 dias), seria mais recomendável o uso de cinco, seis e sete dias de coleta de fezes, devido a maior precisão das estimativas. Esses resultados aproximam-se daqueles obtidos por Vander Noot et al. (1967), os quais verificaram que quatro dias de coleta de fezes foram adequados para ensaios de digestão, pois foi o suficiente para recuperar $99,8 \%$ do oxido crômico administrado aos cavalos, embora sugeriram um período de coleta de cinco dias, objetivando reduzir as diferenças individuais entre os animais. Sibbald e Price (1975) e Vertegen et al. (1973), trabalhando com aves e suínos, respectivamente, constataram também uma redução nos erros-padrão das médias e nos coeficientes de variações com aumento do período de coleta, porém Fialho et al. (1985) não detectaram redução no intervalo de confiança com aumento do período de coleta de cinco para nove dias, em suínos.

A digestibilidade aparente da MS, PB e EB da cana-de-açúcar nos diferentes dias de coleta foi similar aos valores citados por Araújo et al. (1996), que obtiveram valores médios de digestibilidade aparente da MS, PB e EB de 57,46, 55,06 e 54,37\%, respectivamente, utilizando o método do saco de náilon móvel. Figueiredo et al.(1999) também encontraram resultados bastante próximos de digestibilidade aparente da MS, PB, EB e FDN da cana-de-açúcar, cujos valores foram de 55,3,52,3, 54,7 e 44,5\%, respectivamente.

$\mathrm{Na}$ dieta composta de cana-de-açúcar e milho, não foram detectadas diferenças $(\mathrm{P}>0,05)$ entre os dias de coleta de fezes para estimar a digestibilidade aparente da MS, EB e FDN, mas foi verificado um aumento na digestibilidade da $\mathrm{PB}(\mathrm{P}<0,05)$ na coleta de dois dias. Esse fato provavelmente se deve ao pequeno aumento da ingestão de $\mathrm{PB}$, constatado no período de dois dias de coleta de fezes. Pode-se detectar que neste ensaio não houve redução dos erros-padrão das médias dos coeficientes de digestibilidade, à medida que se aumentavam os dias de coleta de fezes, como no primeiro ensaio. Dessa forma, o período de coleta fezes de três a seis dias mostrou-se eficiente. Com esses resultados, confirmam-se os encontrados por Lançanova et al. (1998), os quais verificaram que, em três dias de coleta de fezes, os valores de digestibilidade aparente da MS, EB, FDN e FDA em bovinos são precisos. Entretanto, Sibbald e Price (1975) constataram redução nos erros-padrão das médias para energia metabolizável, determinada com aves, quando se aumentava o período de coleta das excretas. Em pesquisa com ovinos alimentados com $40 \%$ de volumoso e $60 \%$ de concentrado, Ezequiel et al. (1995) constataram que o aumento do período de coleta de fezes de um para cinco dias proporcionou maior confiabilidade nas estimativas dos coeficientes de digestibilidade aparente de MS, PB e EB, em função da redução dos desvios-padrão e erros-padrão das médias. Pelos resultados desta pesquisa, verifica-se uma redução no tempo de coleta de fezes, em relação aos obtidos por Vander Noot et al. (1967), que verificaram que quatro dias de coleta de fezes são adequados, embora sugeriram um período de coleta de cinco dias para reduzir as diferenças individuais entre os animais. Essas divergências se devem possivelmente aos fatores que interferem na digestibilidade dos nutrientes e no fluxo da digesta, como citados por Olsson e Ruudvere (1955) e Warner (1981). 
TABELA 4 - Coeficientes médios de digestibilidade aparente da matéria seca (MS), proteína bruta (PB), energia bruta (EB) e fibra em detergente neutro (FDN) da cana-de-açúcar com os respectivos erros-padrão, para os diferentes dias de coleta.

\begin{tabular}{|c|c|c|c|c|}
\hline \multirow{2}{*}{ Dias de coleta } & \multicolumn{4}{|c|}{ Coeficiente de digestibilidade aparente $(\%)$} \\
\hline & $\mathrm{CDAMS}^{1}$ & $\mathrm{CDAPB}^{1}$ & CDAEB $^{1}$ & CDAFDN $^{1}$ \\
\hline 2 & $54,99 \pm 2,80 \mathrm{a}$ & $51,96 \pm 2,65 \mathrm{a}$ & $54,13 \pm 2,63 \mathrm{a}$ & $43,38 \pm 2,76 a$ \\
\hline 3 & $53,88 \pm 3,07$ a & $48,43 \pm 3,14 \mathrm{a}$ & $52,57 \pm 2,82 \mathrm{a}$ & $42,86 \pm 3,32 \mathrm{a}$ \\
\hline 4 & $54,26 \pm 2,05 \mathrm{a}$ & $50,21 \pm 1,71 \mathrm{a}$ & $53,08 \pm 1,87 \mathrm{a}$ & $42,71 \pm 2,17 \mathrm{a}$ \\
\hline 5 & $53,87 \pm 2,35 \mathrm{a}$ & $50,41 \pm 2,54 \mathrm{a}$ & $52,61 \pm 2,15 \mathrm{a}$ & $42,10 \pm 2,47 \mathrm{a}$ \\
\hline 6 & $54,66 \pm 1,64 \mathrm{a}$ & $51,05 \pm 2,10 \mathrm{a}$ & $53,89 \pm 1,52 \mathrm{a}$ & $43,14 \pm 1,91 \mathrm{a}$ \\
\hline 7 & $55,19 \pm 1,41 \mathrm{a}$ & $51,89 \pm 1,80 \mathrm{a}$ & $54,25 \pm 1,31 \mathrm{a}$ & $43,71 \pm 1,74 \mathrm{a}$ \\
\hline $\mathrm{CV}(\%)^{2}$ & 4,02 & 4,44 & 4,12 & 7,81 \\
\hline
\end{tabular}

${ }^{1}$ Médias seguidas de pelo menos uma mesma letra na mesma coluna não diferem entre si $(P>0,05)$ pelo teste de SNK

${ }^{2}$ Coeficiente de variação

TABELA 5 - Coeficientes médios de digestibilidade aparente da matéria seca (CDAMS), proteína bruta (CDAPB), energia bruta (CDAEB) e fibra em detergente neutro (CDAFDN) da cana-de-açúcar mais milho grão, com os respectivos erros-padrão, para os diferentes dias de coleta.

\begin{tabular}{|c|c|c|c|c|}
\hline \multirow{2}{*}{ Dias de coleta } & \multicolumn{4}{|c|}{ Coeficiente de digestibilidade aparente (\%) } \\
\hline & CDAMS $^{1}$ & $\mathrm{CDAPB}^{1}$ & $\mathrm{CDAEB}^{1}$ & CDAFDN $^{1}$ \\
\hline 2 & $77,67 \pm 1,42 \mathrm{a}$ & $76,32 \pm 2,26 \mathrm{a}$ & $77,63 \pm 1,31 \mathrm{a}$ & $51,03 \pm 5,83 \mathrm{a}$ \\
\hline 3 & $75,96 \pm 1,16 \mathrm{a}$ & $74,71 \pm 2,10 b$ & $75,96 \pm 1,12 \mathrm{a}$ & $48,56 \pm 4,66 \mathrm{a}$ \\
\hline 4 & $76,05 \pm 1,66 \mathrm{a}$ & $74,72 \pm 2,33 b$ & $76,36 \pm 1,62 \mathrm{a}$ & $49,45 \pm 5,38 \mathrm{a}$ \\
\hline 5 & $76,49 \pm 1,85 \mathrm{a}$ & $74,80 \pm 2,52 b$ & $76,89 \pm 1,81 \mathrm{a}$ & $50,99 \pm 5,11 \mathrm{a}$ \\
\hline 6 & $76,28 \pm 1,79 a$ & $74,44 \pm 2,56 b$ & $76,70 \pm 1,77 \mathrm{a}$ & $52,31 \pm 4,89 a$ \\
\hline $\mathrm{CV}(\%)^{2}$ & 1,18 & 0,95 & 1,11 & 4,75 \\
\hline
\end{tabular}

${ }^{1}$ Médias seguidas de pelo menos uma mesma letra na mesma coluna não diferem entre si $(P>0,05)$ pelo teste de SNK

${ }^{2}$ Coeficiente de variação

\section{CONCLUSÕES}

Os períodos de coleta total de fezes de dois a sete dias, para ensaios de digestão com eqüinos alimentados apenas com volumosos, e de três a seis di- as, para eqüinos submetidos às dietas mistas, mostraram-se bastante precisos. Dessa forma, sugere-se um período de cinco dias como forma de padronização de metodologia em ensaios de digestão com eqüinos. 


\section{REFERÊNCIAS BIBLIOGRÁFICAS}

ARAÚJO, K. V.; LIMA, J. A de; TEIXEIRA, J. C. et al. Determinação da digestibilidade aparente dos nutrientes de alguns concentrados e volumosos para eqüinos, pela técnica do saco de náilon móvel. Revista. Brasileira de. Zootecnia. Viçosa, v.25, n.5, p.944-956. set/out. 1996.

CYMBALUK, N. F., CHRISTISON, G. I., LEACH, D. $H$. Nutrient utilization by limit and ad libitum-fed growing horses Journal of Animal Science. Champagin, v.67, n.3, p.414-425, mar.1989.

EZEQUIEL, J. M. B., SAMPAIO, A. A. M., OLIVEIRA, M. Dal S. Efeito do período de coleta sobre a digestibilidade de alguns nutrientes, em ensaios com ovinos. Revista Brasileira de Zootecnia, Viçosa, v.24, n.2, p.261-269, mar/abril. 1995.

FIALHO, E. T., BELLAVER, C., FREITAS, A. R. de et al. Influência da substituição do milho e do farelo de soja no balanço protéico e energético em suínos. Pesquisa Agropecuária Brasileira., Brasília, v.20, n.10, p.1229-1236, out. 1985.

FIGUEIREDO, D. M., ARAÚJO, K. V., LIMA, J. A. F., FIALHO, E. T., MIYAGI, E. S. Valores de digestibilidade de alimentos volumosos para eqüinos. Revista Brasileira de Zootecnia. Viçosa, v.28, n.4, p.766 - 772, jul/ago. 1999.

FRAPE, D. Nutrición y alimentación del caballo. ed Acribia: Zaragoza, 1992, 404p.

FURTADO, C. E., TOSI, H. Gaiola de metabolismo para eqüinos. In: XXXIII REUNIÃO ANUAL DA SOCIEDADE BRASILEIRA DE ZOOTECNIA, Fortaleza, 1996. Anais.... Nutrição de não ruminantes. v.4. Fortaleza: SBZ. 1996. p.192-193, 1996.

HAENLEIN, G. F. W., SMITH, R. C., YOON. Y. M. Determination of the fecal excretion rate of horses with chromic oxide. Journal Animal Science. Champaign, v. 25, n,4, p.1091-1095, nov. 1966.

HINTZ, H. F., LOY, R. G. Effects of pelleting on the nutritive value of horse rations. Journal of Animal Science. Champaign, v. 25, n.4, p.1059, nov. 1966.

MANZANO, A., CARVALHO, R. T. L. de Digestibilidade aparente de uma ração peletizada e do arraçoamento tradicional em eqüinos. Pesquisa Agropecu- ária Brasileira, Brasília, v.13,n.4, p.92-99, abr. 1978.

KNAPKA, J. J., BARTH, K. M., BROWN, D. G. et al. Evaluation of polyethylene, chromic oxide, and cerium144 as digestibility indicators in burros. Journal of Nutrition., Philadelphia, v.92, n.1, p.79-85, maio. 1967.

LANÇANOVA, J. A. C., VILELA, L. M. R., OLIVEIRA, M. Dal S. et al. Digestibilidade aparente de ração completa, com diferentes períodos de colheita de fezes, em bovinos de diferentes grupos genéticos. In: XXXV REUNIÃO ANUAL DA SOCIEDADE BRASILEIRA DE ZOOTECNIA, 1998, Botucatu, Anais.... Nutrição ruminantes. v.1. Botucatu: SBZ. 1998. p. 236-237, 1998.

OLSSON, N., RUUDVERE, A. The nutrition of the horse. Nutrition of Abstracts and Reviews, London, v. 25, n.1, p.1-18, jan. 1955.

ROBINSON, D. W., SLADE, L. M. The current status of knowledge on the nutrition of equines. Journal of Animal Science, Champaign, v.39, n.6, p.1047-1066,dez. 1974.

SIBBALD, I. R., PRICE, K. Variation in the metabolizable energy values of diets and dietary components feed to adult roosters. Poultry Science, Champaign, v.54, n.2, p.448-456. fev. 1975.

SILVA, D. J. 1998. Análise de Alimentos. Métodos Químicos e Biológicos. Viçosa: UFV.166p.

SLADE, L. M., HINTZ, H. F. Comparison of digestion in horses, ponies, rabbits and guinea pigs. Journal of Animal Science, Champaign, v.28, n.6, p.842-843. jun. 1969.

STILLIONS, M. C., NELSON, N. E. Metabolism stall for male equine. Journal of Animal Science, Champaign, v.27, n.1, p.68-72. jan. 1968.

UNIVERSIDADE FEDERAL DE VIÇOSA- UFV. SAEG - Sistema para análises estatísticas e genética. Versão7.1. Viçosa, MG. 150p. (Manual do usuário). 1997.

TODD, K. L., SAUER, W. C., CHRISTOPHERSON, R. J. et al. The effect of level of feed intake on nutrient and energy digestibility and rate of feed passage in horses. Journal Animal Physiol. and Animal Nutrition, Berlin, v.73, n.2, p.140-148, fev. 1995.

VANDER NOOT, G.W., SYMONS, L. D., LYDMAN; R. K. et al. Rate of passagem of various feedstuffs through 
the digestive trat of horses. Journal of Animal Science. Champaign, v.26, n.6, p.1309-1311, jun. 1967.

VAN SOEST, P. J. Development of a comprrehensive sytem of feed analyses and its application to forages. Journal of Animal Science, Champaign, v.26, n.1, p.119-128. Jan. 1967.

VAN SOEST, P. J., ROBERTSON, J. B., LEWIS B. A. Methods for dietary fiber, neutral detergent fiber, and nonstrach plysaccharides in relation to animal nutrition. Journal Dairy Science, Champaign, v.74, n.4, p.35833597, abr. 1991.

VEIGA, J. S. M., ANDREASI, F., PRADA, F. et al. Digestibilidade aparente da matéria seca, em equinos
"1/2 sangue bretão"e "1/2 sangue inglês". Revista da Faculdade de Medicina Veterinária e Zootecnia da USP, São Paulo, v.11, n1, p.7-20, jan. 1974.

VERSTEGEN, M. W. A., CLOSE, W. H., MOUNT. L. E. The optimum duration of metabolic balance experiments with group of pigs. Proc. Nutr. Soc. v.32, n.2, p.72-73, fev.1973.

WARNER, A. C. I. Rate of passage of digesta through the gut of mammals and birds. Nutrition of Abstracts and Reviews, London, v.51, n.12, p.789-820, dez. 1981.

WOLTER, R. Alimentação del Caballo. Zaragosa: Acribia, 1975. 172p. 